\title{
Article
}

\section{Humanities in the undergraduate medical and midwifery curriculumra descriptive Italian comparative study}

Morano, Sandra, Lotti, Antonella, Canepa, Matilde, Sterrantino, Giulia, Beleva, Diliana, Iamnnuzzi, Laura and Downe, Soo

Available at http://clok.uclan.ac.uk/24583/

Morano, Sandra, Lotti, Antonella, Canepa, Matilde, Sterrantino, Giulia, Beleva, Diliana, Iamnnuzzi, Laura and Downe, Soo ORCID: 0000-0003-2848-2550 (2018) Humanities in the undergraduate medical and midwifery curriculum:a descriptive Italian comparative study. Minerva Ginecologica . ISSN 0026-4784

It is advisable to refer to the publisher's version if you intend to cite from the work. 10.23736/S0026-4784.18.04297-1

For more information about UCLan's research in this area go to http://www.uclan.ac.uk/researchgroups/ and search for <name of research Group>.

For information about Research generally at UCLan please go to http://www.uclan.ac.uk/research/

All outputs in CLoK are protected by Intellectual Property Rights law, including Copyright law. Copyright, IPR and Moral Rights for the works on this site are retained by the individual authors and/or other copyright owners. Terms and conditions for use of this material are defined in the policies page.

\section{CLoK}

Central Lancashire online Knowledge www.clok.uclan.ac.uk

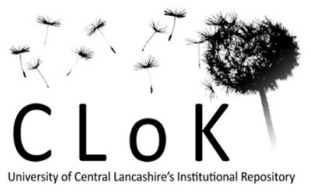




\title{
Humanities in the undergraduate medical and midwifery curriculum: a descriptive Italian comparative study
}

\author{
Sandra MORANO $1 *$, Antonella LOTTI 2, Matilde M. CANEPA 1, \\ Giulia STERRANTINO 1, Diliana BELEVA ${ }^{1}$, Laura IANNUZZI ${ }^{3}$, Soo DOWNE 4
}

1Department of Neuroscience, Rehabilitation, Ophthalmology, Genetics and Maternal-Infant Sciences (DINOGMI), University of Genoa, Genoa, Italy; ${ }^{2}$ Department of Educational Sciences (DISFOR), University of Genoa, Genoa, Italy; ${ }^{3}$ Department of Health Care Professions, Careggi University Hospital, University of Florence, Florence, Italy; ${ }^{4}$ Research in Childbirth and Health Unit (ReaCH), School of Community Health and Midwifery, University of Central Lancashire, Preston, UK

*Corresponding author: Sandra Morano, Department of Neuroscience, Rehabilitation, Ophthalmology, Genetics and Maternal-Infant Sciences (DINOGMI), University of Genoa, Largo Paolo Daneo 3, 16132 Genoa, Italy. E-mail: sandra.morano@unige.it

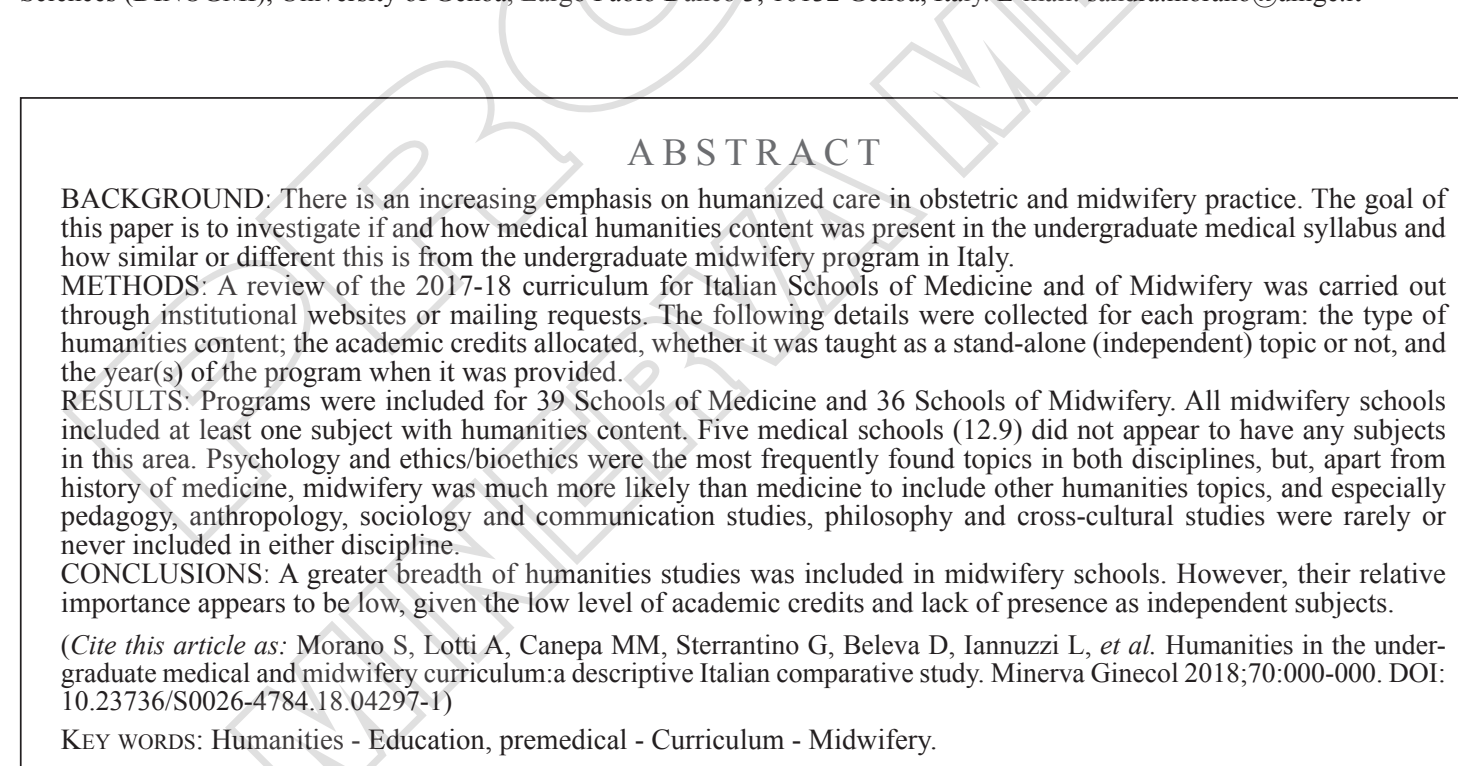

$\mathrm{U}$ ntil some centuries ago, medicine and humanities were linked together. ${ }^{1}$ It has been argued that the division between the mind and the body, proposed by Descartes ${ }^{2}$ was a direct source of the paradigmatic division of theories of human epistemology into two paradigms: the positivist ("mind") approach of hard science, and the consequent bio-mechanical framing of medicine, and the more subjectivist 'body' approach, which has a more socio-cultural frame of reference, captured in the general area of the humanities. 
Mangione has recently acknowledged the potential for a positive role of the humanities in medical education, within a critique that sees current medical training as strongly focused on hiding emotions, observing signs and facts, doing diagnosis, and prescribing therapy. Mangione recognizes that these biomedical norms can only be addressed if there is a critical reconsideration of medicine's skepticism of the humanities as being slippery, non-metric, hard to define, and essentially incompatible with an evidence-based approach. ${ }^{3}$ This builds on the call from Zannini a decade ago for the need to restart the relationship between medicine and the humanities, and between the arts and the sciences. ${ }^{4}$

The scope of "medical humanities" includes classic humanities (literature, philosophy, ethics, history and religion), social science (anthropology, cultural studies, psychology, sociology), and the arts (theatre, cinema and visual arts) and their application to medical education and practice. The humanities and arts provide insight into the human condition, suffering, personhood, and our responsibility to each other, and they offer an historical perspective on medical practice. 5,6

In historical terms, a single faculty - facultas artistarum - graduated students in Medicine and granted them a degree in medicine and philosophy. In historical terms, until the $19^{\text {th }}$ century, medical students had to attend a two-year course of philosophical studies which provided them with adequate knowledge of general human problems, and a solid education in rational thought, logic, and philosophy representing the two pillars of methodological training, and professional values. ${ }^{1}$

In Italy the separation between the so-called "metaphysical" sciences and naturalistic positivistic teaching was completed in 1860 , when the discipline of medicine was transformed into a purely naturalistic faculty. However, more recently, anthropological medical research began to (re)focus on the meaning of illness and treatment, and on the need to place the patient, intended as a human being, at the center of all the process of care. ${ }^{7}$ Over the last four or five decades, the US has gradually introduced medical humanities into the medical curricula, followed by other English-speaking countries. Despite this, the discussion about the place of the humanities (often framed as an ancient university tradition, ${ }^{8}$ and scientific education, is still continuing. ${ }^{9}$ As Cooper had noted more recently, medical scientific education seems still to be framed by a positivistic-reductionist paradigm, and a biomedical perspective, and does not comprehensively recognize the totality of individual patient needs. ${ }^{10}$

In Italy the debate about the nature of medical education has been present for at least 50 years. It has occurred via the Italian Society of Medical Education (SIPEM) from 1984, which has educated academic teachers, and worked as an advisor for the Permanent Conference of Medical Deans and Educational vice-Deans. Although on a theoretical perspective, medical humanities are considered important and they are present in the syllabus, they are not yet integrated as a "forma mentis" in the academic mood as a whole.

Prior to undertaking the review reported in this paper, one relevant systematic review of the area was located. ${ }^{1}$ This included Italian literature up to 2011 reporting on the state of medical humanities $(\mathrm{MH})$ in the Italian Schools of Medicine, which includes medical students, and students of other health professions. The results confirm that the inclusion of MH teaching facilitates the development of an empathic attitude and of interpretative abilities and the understanding and self-care and acquisition of ethical sense and of responsibility. The authors note that $\mathrm{MH}$ includes a wide area dedicated to narrative medicine, that is a precondition for creating or discovering a new relationship between doctors and patients: "It is not a new fashion, but the rediscovery and reaffirmation of the role and primary task of being a doctor, which implies listening, attention, respect, sympathy, sharing, participation, empathy." 11

The systematic review provides some interesting considerations about the definition of $\mathrm{MH}$, subdivided into two main classes, the first one referring to the field of knowledge introduced in syllabuses (disciplines such as: medical psychology, literary criticism, health anthropology, history of health, ethics, but also religion, theatre, figurative arts, music, law, philosophy, sociology). The second one comes from a teleological 
vision, according to which four different functions relative to $\mathrm{MH}$ can be listed: development of empathic attitude; development of interpretative abilities; understanding and self-care; acquisition of an ethical sense of responsibility. ${ }^{1}$

A very recent study has also examined $\mathrm{MH}$ in medical curricula in Italy, and in Spain. ${ }^{12}$ The authors found that all included curriculum there were disciplines which could be considered belonging to $\mathrm{MH}$ area, such as history of medicine, philosophy, anthropology and literature. However, apart from history of medicine and the visual arts, Spanish universities were more likely than Italian universities to include each of the specific MH subjects that were examined. Although both countries had low academic credits allocated to $\mathrm{MH}$ subjects Italian universities were more likely than Spanish ones to allocate less than two credits to these topics and more likely to include them into other modules, rather than as stand -alone topics, suggesting that they generally had lower levels of important in Italy than in Spain.

These findings might have particular relevance for those working in maternity care in Italy. The Italian Health System has recently been under EU observation regarding reproductive health policies. Italy has a very low fertility rate, and one of the highest caesarean section rates in the world (the second highest in Europe). ${ }^{13}$ All of this suggests that there is scope to improve the orientation of maternity care in Italy. Obstetric and midwifery students deal with life and death, sometimes simultaneously, and they are exposed to a wide spectrum of feelings. A dehumanized philosophy of care that is focused on technological procedures and population-based protocols hinders clinicians from making appropriate emotional and psychological connections with childbearing women and their families. This is compounded by the way maternity services are organized, and by the design of maternity facilities and organizations, which do not foster positive empathic relationships between obstetricians, midwives, and women and families using the services. The expansion (or even the introduction) of $\mathrm{MH}$ into undergraduate curricula might provide a basis for integrating the techno-scientific and psycho-social perspective of health care providers, and provide a catalyst for improving maternity care environments for staff and service users.

As a first step in better integration of $\mathrm{MH}$ into the medical (obstetric) and midwifery curricula, this study builds on that of Orefice ${ }^{12}$ by comparing the degree to which $\mathrm{MH}$ is integrated into the medical and the midwifery curricula in public universities in Italy, and the relative weight given to these subjects.

The midwifery program Italy is a bachelor program, lasting 3 years and 180 Italian University Credits (1ECTS $=30$ hours). The undergraduate medical program is at Masters degree level, (European Qualification Framework), and lasts six years and 360 Italian University credits (1ECTS $=25$ hours). In both cases, according to the Italian Ministry of University standards, the syllabus must be planned by the Core Faculty that prescribes a list of compulsory and optional disciplines and subjects.

\section{Materials and methods}

Our study was carried out in public universities in Italy, analyzing the undergraduate medical program and the bachelor of midwifery program relative to year 2017-2018. The included syllabi were found in their institutional websites on the Internet.

To structure the data collection we analyzed the following disciplines: general psychology, clinical psychology, communication/counselling, anthropology, history of medicine, pedagogy, intercultural/multicultural, ethics/bioethics, sociology and philosophy. We have considered how often that discipline appears in the curriculum and we have defined it, like in Orefice's study, ${ }^{12}$ as the number of subjects. We logged the relative academic credits (ECTS) awarded to humanities subjects for each program, the year the $\mathrm{MH}$ content was taught, and whether it was taught as a stand-alone subject or not.

\section{Results}

We located curriculum for 36 public midwifery schools (there are no private midwifery schools in Italy) and for 39 of 40 medical schools (36 public and 3 private) (Table I).

At least one humanities topic was present in 
TABLE I.-Medical Humanities in Italian Schools of Medicine and Schools of Midwifery.

\begin{tabular}{|c|c|c|c|c|}
\hline \multirow{2}{*}{$\begin{array}{l}\text { Discipline } \\
\text { Clinical psychology }\end{array}$} & \multicolumn{2}{|c|}{$\begin{array}{l}\text { Number of Medical Schools presenting } \\
\text { subjects in the curriculum }\end{array}$} & \multicolumn{2}{|c|}{$\begin{array}{l}\text { Number of Midwifery Schools } \\
\text { presenting subjects in the curriculum }\end{array}$} \\
\hline & $27 / 39$ & $69.23 \%$ & $29 / 36$ & $80.56 \%$ \\
\hline History of medicine & $27 / 39$ & $69.23 \%$ & $14 / 36$ & $38.89 \%$ \\
\hline Ethics and bioethics & $18 / 39$ & $46.15 \%$ & $28 / 36$ & $77.78 \%$ \\
\hline General psychology & $15 / 39$ & $38.46 \%$ & $28 / 36$ & $77.78 \%$ \\
\hline Anthropology & $9 / 39$ & $23.08 \%$ & $18 / 36$ & $50 \%$ \\
\hline Pedagogy & $8 / 39$ & $20.51 \%$ & $23 / 36$ & $63.89 \%$ \\
\hline Communication and counselling & $7 / 39$ & $17.95 \%$ & $11 / 36$ & $30.56 \%$ \\
\hline None humanities & $5 / 39$ & $12.82 \%$ & $0 / 36$ & $0 \%$ \\
\hline Sociology & $3 / 39$ & $7.69 \%$ & $18 / 36$ & $50 \%$ \\
\hline Philosophy & $1 / 39$ & $2.56 \%$ & $0 / 36$ & $0 \%$ \\
\hline Interculturality/ multiculturality & $0 / 39$ & $0 \%$ & $4 / 36$ & $11.11 \%$ \\
\hline
\end{tabular}

all midwifery schools and in $34 / 39(87.2 \%)$ of medical schools.

Humanities show a huge difference among different schools, due to universities autonomy, rather than geographical variations.

The next section presents more detailed data on each MH topic.

TABLE II.-General psychology: characteristics of disciplines in Italian Schools of Medicine and Schools of Midwifery.

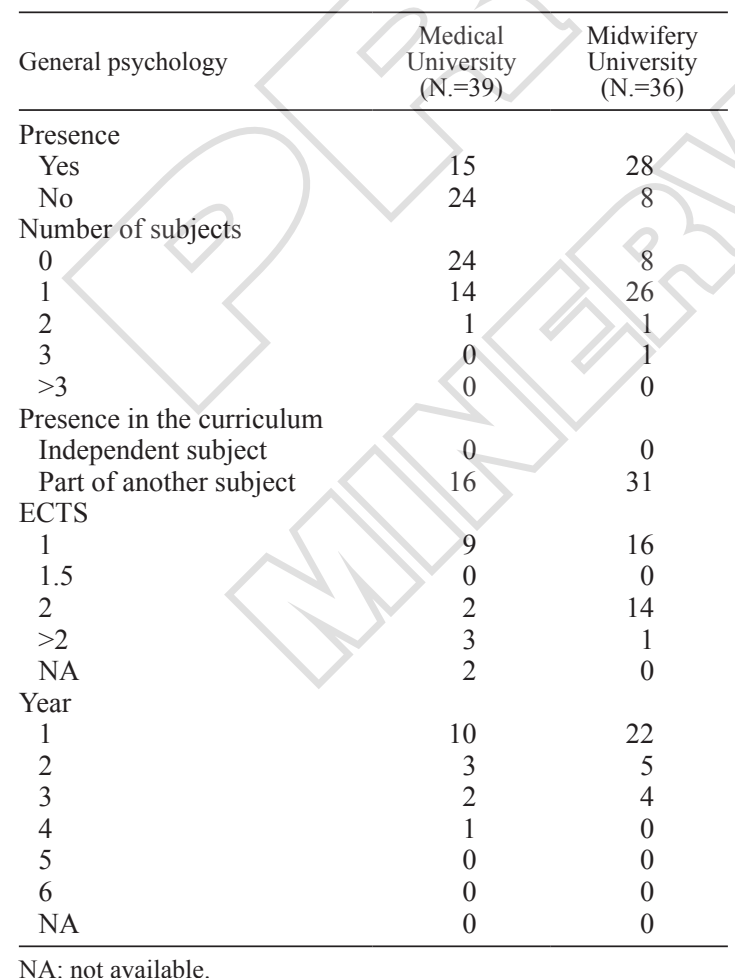

NA: not available.
General and clinical psychology

Table II, III below indicates that general psychology is taught in midwifery schools in the first year, while clinical psychology is taught during the whole three years program so showing that anyway Psychology per se is taught in all Italian Midwifery Schools. As Table I shows, psychology is less likely to be taught in pre-registration medicine. Where it is present, general psychology is also taught in the first year, but then there is a gap, with clinical psychology coming back into the program in the fifth year.

In both disciplines, the modal allocation of academic credits is 1 for both types of psychology, though an almost equal number of midwifery schools allocate 2 credits for both subjects. This is also true for clinical psychology in medical schools, but not for general psychology. In both disciplines, some schools allocate more than two credits to both subjects, revealing a large degree of variation across the country, but not by discipline. In both cases, this subject is always taught as part of another topic, and not as an independent module (Table II).

In Midwifery Schools Clinical Psychology is taught in 29/36 (80.5\%), 1.66 ECTS credits (49.8h), while in Medical Schools Clinical Psychology is present in 27/39 schools (69.2\%) 1.7 ECTS credits (42.4h), so we can say that, regard the hours amount, Midwifery students exposure to Clinical Psychology is roughly the same compared to the medical students attending the fewer Schools presenting Clinical Psychology in their curricula (Table III). 
TABLE III._Clinical psychology: characteristics of disciplines in Italian Schools of Medicine and Schools of Midwifery.

\begin{tabular}{|c|c|c|}
\hline Clinical psychology & $\begin{array}{l}\text { Medical } \\
\text { University } \\
(\mathrm{N} .=39)\end{array}$ & $\begin{array}{c}\text { Midwifery } \\
\text { University } \\
(\mathrm{N} .=36)\end{array}$ \\
\hline \multicolumn{3}{|l|}{ Presence } \\
\hline Yes & 27 & 29 \\
\hline No & 12 & 7 \\
\hline \multicolumn{3}{|l|}{ Number of subjects } \\
\hline 0 & 12 & 7 \\
\hline 1 & 18 & 29 \\
\hline 2 & 7 & 0 \\
\hline 3 & 2 & 0 \\
\hline$>3$ & 0 & 0 \\
\hline \multicolumn{3}{|l|}{ Presence in the curriculum } \\
\hline Independent subject & 0 & 0 \\
\hline Part of another subject & 38 & 29 \\
\hline \multicolumn{3}{|l|}{ ECTS } \\
\hline 1 & 18 & 13 \\
\hline 1.5 & 0 & 0 \\
\hline 2 & 12 & 13 \\
\hline$>2$ & 7 & 3 \\
\hline NA & 1 & 0 \\
\hline \multicolumn{3}{|l|}{ Year } \\
\hline 1 & 1 & 10 \\
\hline 2 & 3 & 9 \\
\hline 3 & 7 & 10 \\
\hline 4 & 6 & 0 \\
\hline 5 & & 0 \\
\hline 6 & 5 & 0 \\
\hline NA & 2 & 0 \\
\hline
\end{tabular}

NA: not available.

\section{Communication and counselling}

This subject is taught in $30.5 \%$ of Midwifery Schools, and only in $17.9 \%$ of Medical Schools.

However, in $50 \%$ of the medical schools where it is taught, this is as an independent topic, as opposed to less than $25 \%$ for midwifery schools where the topic is taught. This suggests that a few medical schools might be realizing that such skills are essential for good medical care, and they need to be taught explicitly, whereas they are assumed to be more innate for those intending to be midwives. The credit allocation for these sessions varies, with midwifery schools tending to give them higher credit ratings, but with a higher proportion of medical than midwifery schools giving this topic a credit rating of over 2. Midwifery schools tend to return to this topic throughout the three years, but medical schools appear to see it as more foundational, as it only appears in the
TABLE IV.-Communication and counselling: characteristics of disciplines in Italian Schools of Medicine and Schools of Midwifery.

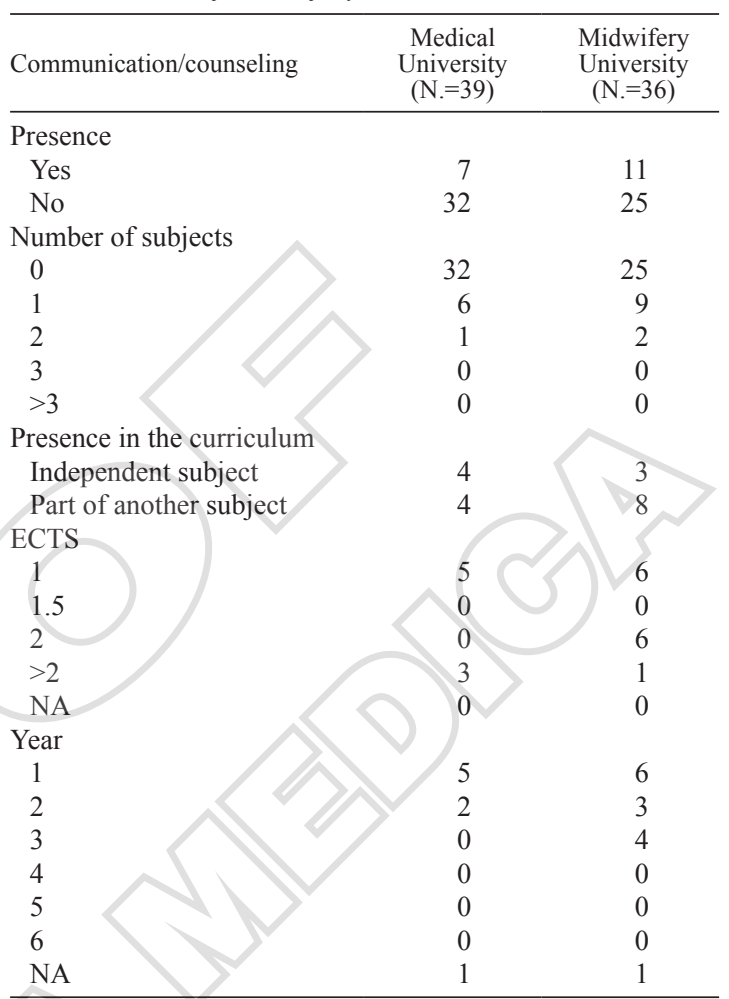

NA: not available.

first two years of the six-year medical program (Table IV).

\section{Anthropology}

Anthropology is twice as likely to be present in midwifery schools as in medical schools $(50 \%$ vs. $23.1 \%$ ). However, as table five indicates, as for other humanities subjects, for the few medical schools that do include it, the academic credit rating tends to be higher than for midwifery schools (where this rating was available), and it is more likely to be treated as an independent topic. For both disciplines, where the topic was provided it was most likely to be taught in year one (Table V).

\section{Pedagogy}

Pedagogy is much more likely to be taught in midwifery schools than in medical schools (68.3\% vs. $20.5 \%)$. As table six demonstrates, the 
TABLE V.-Anthropology: characteristics of disciplines in Italian Schools of Medicine and Schools of Midwifery.

\begin{tabular}{ccc}
\hline & Medical & Midwifery \\
Anthropology & University & University \\
& $(\mathrm{N} .=39)$ & $(\mathrm{N} .=36)$ \\
\hline
\end{tabular}

Presence

Yes

No

Number of subjects

0

1

2

3

$>3$

Presence in the curriculum

Independent subject

Part of another subject ECTS

1

1.5

2

$>2$

NA

Year

1

2

3

4

5

6

NA

NA: not available.

pattern persists here as for other subjects: where medical schools do include pedagogy, it is more likely to be treated as an independent topic, and more likely to be given over 2 academic credits. In both cases, the topic was taught by some universities throughout the pre-registration course, though in midwifery it was most likely to be in year one (Table VI).

\section{Ethics/bioethics}

This topic was taught in nearly half of all medical schools (46.2\%) and in more than three quarters of midwifery schools (77.8\%). Given the extensive ethical issues in medicine in general, and obstetrics and midwifery in particular, it is rather surprising that this topic does not feature prominently in all of the included curriculum. In this case, the allocation of credits was roughly similar between both disciplines, though, as in other topics, there was clear variation amongst schools within both disciplines, with credits ranging
TABLE VI.-Pedagogy: characteristics of disciplines in Italian Schools of Medicine and Schools of Midwifery.

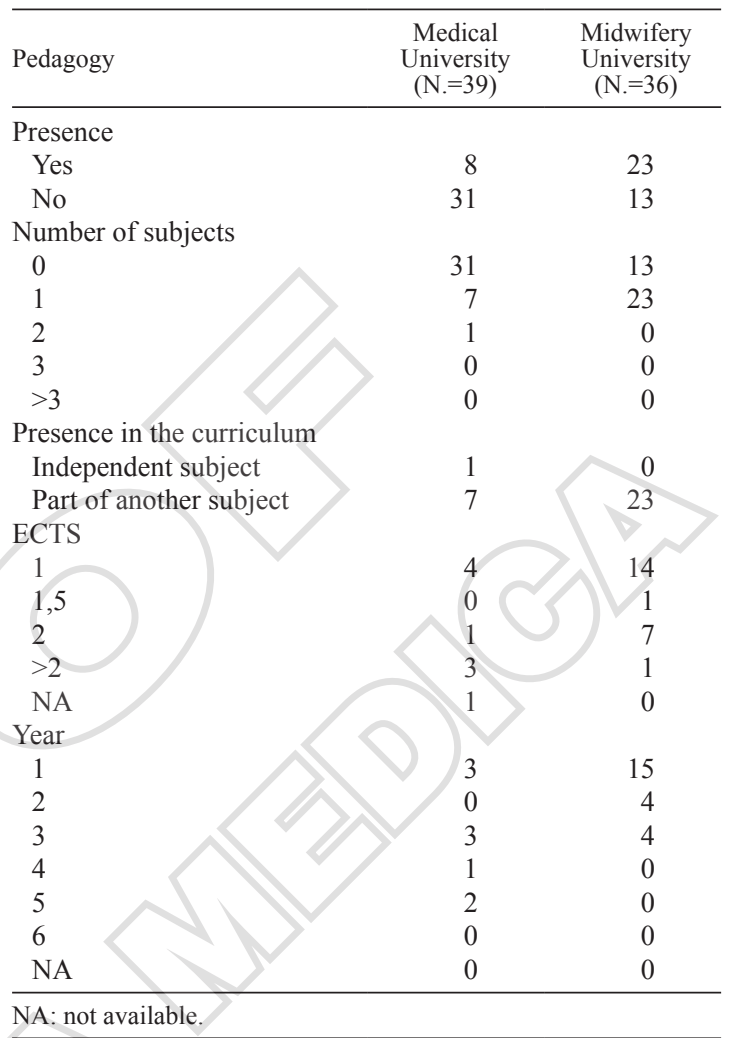

from 1 to more than 2 in both cases. Both disciplines provided teaching in this area throughout the pre-registration course. As is the case for the other topics, medical schools were more likely to give this topic independent status, with half of those providing it doing so, compared to none of the midwifery schools (Table VII).

\section{Sociology}

This topic was overwhelmingly more likely to be present in midwifery schools $(50 \%)$ than in medical schools (7.7\%). The credit allocation and the years of teaching were similar between the two disciplines, though; again, while no midwifery schools offered this as an independent subject, two of the three medical schools did so (Table VIII).

\section{History of medicine}

This was the only topic that was more likely to be taught in medical schools $(69.2 \%)$ than in mid- 
TABLE VII.-Ethics and bioethics: characteristics of disciplines in Italian Schools of Medicine and Schools of Midwifery.

\begin{tabular}{|c|c|c|}
\hline Ethics and bioethics & $\begin{array}{c}\text { Medical } \\
\text { University } \\
(\mathrm{N} .=39)\end{array}$ & $\begin{array}{c}\text { Midwifery } \\
\text { University } \\
(\mathrm{N} .=36)\end{array}$ \\
\hline \multicolumn{3}{|l|}{ Presence } \\
\hline Yes & 18 & 28 \\
\hline No & 21 & 8 \\
\hline \multicolumn{3}{|l|}{ Number of subjects } \\
\hline 0 & 21 & 8 \\
\hline 1 & 15 & 24 \\
\hline 2 & 2 & 4 \\
\hline 3 & 1 & 0 \\
\hline$>3$ & 0 & 0 \\
\hline \multicolumn{3}{|l|}{ Presence in the curriculum } \\
\hline Independent subject & 7 & 0 \\
\hline Part of another subject & 11 & 28 \\
\hline \multicolumn{3}{|l|}{ ECTS } \\
\hline 1 & 5 & 10 \\
\hline 1.5 & 0 & 0 \\
\hline 2 & 4 & 12 \\
\hline$>2$ & 5 & 6 \\
\hline NA & 4 & \\
\hline \multicolumn{3}{|l|}{ Year } \\
\hline 1 & 10 & 7 \\
\hline 2 & 1 & 6 \\
\hline 3 & 2 & 15 \\
\hline 4 & 1 & 0 \\
\hline 5 & 3 & 0 \\
\hline 6 & 1 & 0 \\
\hline NA & 0 & 0 \\
\hline
\end{tabular}

wifery schools as a stand-alone subject (38.9\%). This might be because it is a topic particularly aligned with the interests of medical students, and not so much with midwifery students, who are more likely to study the history of midwifery. However, the history of medicine is important for all disciplines and it explains how current biomedical norms about health and wellbeing have evolved, so it is surprising that it is not present in more midwifery schools, and in all medical schools. Again, though medicine is more likely to see this as an independent topic, the credit ratings are roughly proportional across disciplines, but much more variable within them. In both cases, teaching of the history of medicine tends to take place earlier in the program (Table IX).

Philosophy (Literature and Arts) and inter-multicultural

For both of these topics detailed analysis is not given, because no midwifery schools (and only
TABLE VIII.-Sociology: characteristics of disciplines in Italian Schools of Medicine and Schools of Midwifery.

\begin{tabular}{|c|c|c|}
\hline Sociology & $\begin{array}{l}\text { Medical } \\
\text { University } \\
(\mathrm{N} .=39)\end{array}$ & $\begin{array}{c}\text { Midwifery } \\
\text { University } \\
(\mathrm{N} .=36)\end{array}$ \\
\hline \multicolumn{3}{|l|}{ Presence } \\
\hline Yes & 3 & 18 \\
\hline No & 36 & 18 \\
\hline \multicolumn{3}{|c|}{ Number of subjects } \\
\hline 0 & 36 & 18 \\
\hline 1 & 2 & 18 \\
\hline 2 & 1 & 0 \\
\hline 3 & 0 & 0 \\
\hline$>3$ & 0 & 0 \\
\hline \\
\hline Independ & 1 & 0 \\
\hline & 2 & 18 \\
\hline \multicolumn{3}{|c|}{ ECTS } \\
\hline $\begin{array}{l}1.5 \\
1.5\end{array}$ & $\begin{array}{l}2 \\
0\end{array}$ & $\begin{array}{r}12 \\
0\end{array}$ \\
\hline & $\begin{array}{l}1 \\
0\end{array}$ & $\begin{array}{l}6 \\
0\end{array}$ \\
\hline NA & 0 & 0 \\
\hline \multicolumn{3}{|l|}{ Year } \\
\hline 1 & 1 & 10 \\
\hline 2 & 1 & 2 \\
\hline 3 & 0 & 6 \\
\hline 4 & 0 & 0 \\
\hline 5 & 0 & 0 \\
\hline 6 & 1 & 0 \\
\hline NA & 0 & 0 \\
\hline
\end{tabular}

one medical school) provided the former, and no medical schools provided the latter, so comparative analysis is not possible.

\section{Discussion}

The findings show that, while all midwifery schools offer at least some humanities-based education, there are still some medical schools that appear to provide none. In general, of the schools that do offer at least some, the only area in which medical schools are more likely than midwifery schools to do so is the history of medicine. Rather surprisingly, less than half of medical schools offer teaching in ethics and bioethics, which raises a large number of questions about the preparedness of medical staff to cope with the intense ethical problems in decision making in maternity care. Equally striking is the fact that, although midwifery schools are completely focused on maternity 
TABLE IX.- History of Medicine: characteristics of disciplines in Italian Schools of Medicine and Schools of Midwifery.

\begin{tabular}{lcc}
\hline History of medicine & $\begin{array}{c}\text { Medical } \\
\text { University } \\
(\mathrm{N} .=39)\end{array}$ & $\begin{array}{c}\text { Midwifery } \\
\text { University } \\
(\mathrm{N} .=36)\end{array}$ \\
\hline Presence & 27 & 14 \\
Yes & 12 & 22 \\
No & 12 & 22 \\
Number of subjects & 26 & 14 \\
0 & 1 & 0 \\
1 & 0 & 0 \\
2 & 0 & 0 \\
3 & & \\
$>3$ & 8 & 0 \\
Presence in the curriculum & 19 & 14 \\
Independent subject & & \\
Part of another subject & 7 & 6 \\
ECTS & 0 & 1 \\
1 & 14 & 6 \\
1.5 & 3 & 1 \\
2 & 3 & 0 \\
$>2$ & & \\
NA & & \\
Year & 21 & 11 \\
1 & 3 & 3 \\
2 & 3 & 0 \\
3 & 0 & 0 \\
4 & 0 & 0 \\
5 & 0 & 0 \\
6 & 0 & \\
NA & & \\
\hline NA & & \\
\hline
\end{tabular}

NA: not available.

care, some do not seem to provide training in this area.

In a parallel area, education in communication and counselling is very poorly represented in both disciplines. This is a matter for considerable concern, given the current recognition of the prevalence of, and harm caused by, disrespectful and abusive care in childbirth. ${ }^{14,15}$ As the following statement suggests, this appears to suggest that those designing curriculum think that technical training should always be valued over education and training in empathic skills and attitudes:

"...Looking back at the statement I so frequently hear: that people would rather have a doctor who is skilled than one who is compassionate. I wonder why so many feel the need to frame things in such a way, as if it is a zero-sum game. Is it not possible, it is not necessary to be both? Is this not the foundation of trust? And, if it is, much more is at stake when we think about the ways our future caregivers are educated. "16

Anthropology, sociology and pedagogy are all much more likely to be present in the midwifery curriculum than the medical one. All of these topics enable students to understand how society shapes the views, experiences and expectations of health care users, and how they learn (about health and wellbeing and positive lifestyles, for instance). All are therefore valuable as foundational subjects for professional practice.

It is striking that both philosophy and multiculturalism were rarely present in either discipline. This is of particular concern as issues of multiculturalism, gender identify, migration, and the very philosophical foundations of medical and midwifery care are coming under debate. It is hard to see how health care practitioners can be prepared to deal with these issues if they have no grounding in them at the pre-registration level.

In general, both midwifery and medical schools have tended to place humanities earlier in their curriculum, as foundational studies. However, there appear to be a few cases where medical schools have strongly valued the humanities, and given them more independent space and higher credit ratings than midwifery schools have tended to do, as well as returning to them at later stages. It is possible that this is aided by the fact that the medical curriculum is twice as long as the midwifery one, affording more space for expansion in these areas. However, the medical curriculum is also very crowded even over six years, so universities that have allocated this space have made a conscious decision to do so, in preference to other topics.

Contrary to our expectation, the biggest variations in topic provision, credit allocation, and timing in the curriculum were within and not between disciplines. This means that people with a medical or a midwifery qualification in Italy may have very different amounts of training in and understanding of humanities across Italy. This could be problematic in terms of the capacity of some practitioners to understand and deal with the increasingly relevant socio-cultural factors that operate in the provision of good quality obstetric and midwifery care:

"Exposure to the humanities is associated with both important personal qualities and prevention 
of burnout. In fact, one could argue that some of the qualities we measured (tolerance for ambiguity, empathy, emotional appraisal of self and others, resilience) are, together with wisdom, fundamental components of professionalism. Hence, if we wish to create wiser, more tolerant, empathetic, and resilient physicians, we might want to reintegrate the humanities in medical education. This is nothing new. "3

The body of literature stressing the importance of socio-cultural aspects of medicine in particular, and maternity care in general, has been growing steadily over the last couple of decades.

In maternity care, this has included debates about respectful care ${ }^{15}$ and about the need to balance safety with positive maternal and family experiences. ${ }^{17}$ Teaching humanities to pre-registration medical students, and to other health professionals, is one way of encouraging a reorientation to the psychosocial aspects of health and wellbeing. In order to understand how this might be currently operationalized for medical students who might become obstetricians, and for midwives, our study has built on recent findings of the teaching of humanities in Italian and Spanish medical schools, ${ }^{12}$ adding the extra comparative dimension between medical and midwifery schools in Italy.

From this perspective, the aim of our study, despite the availability of a recent review confronting Italian and Spanish MH curricula, was to highlight, compare and check the value of the exposure of Medicine and Midwifery young student population as a whole.

The two studies compare some different disciplines: Orefice analyzed some disciplines (philosophy, history of medicine, sociology, anthropology, literature, religion, cinema, visual arts, music); our study did not analyzed literature, religion, visual arts, music, cinema but explored ethics and bioethics, that Orefice considered as philosophy, history of medicine, sociology and anthropology and added also psychology (general psychology and clinical psychology), communication and pedagogy because we think that psychology, communication/counselling and pedagogy could facilitate some methods which are useful to put into practice the bio-psycho-social paradigm.

Our idea is that medical humanities could help to develop the empathy and the ability to under- stand and to feel the subjective point of view of our patients; disciplines like psychology, communication/counselling and pedagogy usually teach, in interactive way, how to educate and to listen in an active way our patients.

The two studies compare different objects: Orefice analyses Medical program in Italy and in Spain, our study analyses Medical program and midwife program.

If we take into account only the medical programs we notice that Orefice studies 42 Medical programs and our study analyses 39 Medical programs, and there is no difference in the two studies for anthropology (23\% in our study, $26.2 \%$ in Orefice). There are some slight differences in History of Medicine and Ethics due to the fact that they belong to the same academic area in Italy and they are considered as separate in Orefice study.

We are perfectly aware of the difference regarding the two different professional pathway degrees, responsibility and competences, that would lead us to a very difficult endeavor, rather unique in the current educational landscape. This study could show us even little changes, if any, in Orefice findings, and could call for the opportunity of increasing the number of educational studies, which lack, together with a multidisciplinary and multi-professional approach, actually affects only a small part of academic world. ${ }^{1}$ Moreover, putting near two different educational schools, considering for the first time their students $\mathrm{MH}$ exposure in the same pictures and tables, does show a first even quantitative picture able to bear witness how education changed or still needs to achieve in this field.

\section{Conclusions}

This study has shown that medical humanities are poorly represented in pre-registration programs for midwifery, and are even less prevalent in Italian undergraduate medical programs. There is large variation within both disciplines in the medical humanities taught, the degree of independence accorded to them, and the allocation of academic credits. In some subjects there is also variation in the timing of the teaching of these subjects across the years of the pre-registration program. 
This research reveals the presence of these subjects in the syllabi, but information is lacking about the competences and learning outcomes that students should acquire at the end of their training.

It is necessary and urgent that medical doctors and midwives are very well trained and assessed in the field of Medical Humanities to guarantee a high-quality care to women during pregnancy labor and birth. New research is required to assess the curriculum design of medical humanities in the medical and health professions to optimize the best possible care for women, babies and families, and to ensure "well rounded" health professionals.

Medical humanities are not a miraculous drug, but they do underpin the ability of health professionals to recognize and develop skills in positive human relationships, empathy, effective listening and communication, and understanding the social and cultural contexts of individuals and how this affects their needs, values and responses to the maternity care system. It is now critical for those teaching doctors, midwives, and obstetricians to examine best practice in pre-registration in this area, as exemplified in midwifery and medical schools that integrate and value effective education in these areas. It is also important to assess the impact of such teaching on the skills, attitudes, practices, values and resilience of the resulting maternity care practitioners, and the experiences and outcomes for the women and families using the maternity services that they provide.

\section{References}

1. Fieschi L, Matarese M, Vellone E, Alvaro R, De Marinis MG. Medical humanities in healthcare education in Italy: a literature review. Ann Ist Super Sanita 2013;49:56-64.
2. Cartesio R. Discorso sul metodo, a cura di G. De Ruggiero. Milan: Mursia; 2009.

3. Mangione S, Chakraborti C, Staltari G, Harrison R, Tunkel AR, Liou KT, et al. Medical Students' Exposure to the Humanities Correlates with Positive Personal Qualities and Reduced Burnout: A Multi-Institutional U.S. Survey. J Gen Intern Med 2018;33:628-34.

4. Zannini L. Medical Humanities e Medicina Narrativa. Milan: Cortina Ed; 2008.

5. Pancino C. Il bambino e l'acqua sporca. Storia dell'assistenza al parto dalle mammane alle ostetriche. Milan: Franco Angeli; 1985.

6. Filippini NM. Generare, partorire, nascere: una storia dall'antichità alla provetta. Rome: Ed. Viella; 2017.

7. Good BJ. Narrare la malattia. Lo sguardo antropologico sul rapporto medico-paziente. Turin, Italy: Edizioni di Comunità; 1999 .

8. Evans HM. Medical humanities: stranger at the gate, or long-lost friend? Med Health Care Philos 2007;10:363-72.

9. Brody H. Defining the medical humanities: three conceptions and three narratives. J Med Humanit 2011;32:1-7.

10. Cooper RA, Tauber AI. Viewpoint: new physicians for a new century. Acad Med 2005;80:1086-8.

11. Parizzi F. La medicina Narrativa. L'arco di Giano 2009;61:165-73.

12. Orefice C, Pérez J, Banõs JE. The presence of humanities in the curricula of medical students in Italy and Spain; 2018 [Internet]. Available from: https://www.sciencedirect.com/ science/article/pii/S1575181318300056 [cited 2018, Oct 9].

13. European perinatal health report: Health and care of pregnant women and babies in Europe in 2010; [Internet]. Available from: http://www.europeristat.com/reports/europeanperinatal-health-report-2010.html [cited 2018, Oct 9].

14. Cedefop. National qualifications framework developments in Europe 2017; [Internet]. Available from: http://data. europa.eu/doi/10.2801/029873 [cited 2018, Oct 9].

15. WHO statement. The prevention and elimination of disrespect and abuse during facility-based childbirth. Geneva: WHO; 2015.

16. Piemonte N. More to the story: how the medical humanities can learn from and enrich health communication studies. Rev Comm 2017;17:137-48.

17. WHO recommendations on antenatal care for a positive pregnancy experience. WHO; 2016 [Internet]. Available from: www.who.int/reproductivehealth/publications/maternal_perinatal health/anc-positive-pregnancy-experience/en/ [cited 2018, Ōct 9].

Conflicts of interest.-The authors certify that there is no conflict of interest with any financial organization regarding the material discussed in the manuscript.

Funding.- This paper was a proposal within the COST Action EU COST Action IS1405: BIRTH, supported by the COST Programme as part of EU Horizon 2020.

Authors' contributions.-Sandra Morano proposed to check and compare the presence of MH in Italian medical and midwifery schools in order to facilitate education to empathy and compassionate care; Antonella Lotti, from a medical pedagogic perspective, helped developing the hypothesis on a theoretical and educative background; Diliana Beleva and Giulia Sterrantino checked all Italian Medical and Midwifery school curricula; Matilde Canepa analyzed the research findings comparing outcomes and showing commonalities and differences; Laura Iannuzzi contributed with suggestions and comments; Soo Downe helped with important advices, supporting the paper aim and contributing to its development.

Article first published online: October 2, 2018. - Manuscript accepted: August 28, 2018. - Manuscript received: August $20,2018$. 